\title{
The Meanings and Structural Forms of the Measure Word for Nouns in Chinese and Vietnamese
}

\author{
Quoc Hung Le Pham \\ College of Chinese Language and Literature, Wuhan University \\ Hubei, China \\ E-mail: guoxiongpham@hotmail.com
}

Received: April 21, $2020 \quad$ Accepted: February 24, $2021 \quad$ Published: February 25, 2021

doi:10.5296/ijl.v13i1.16890

URL: https://doi.org/10.5296/ijl.v13i1.16890

\begin{abstract}
In the field of language research, the measure word is an interesting research topic. In the world language, some languages have measure words, some languages have not. Both Chinese and Vietnamese belong to the language rich in measure words, but due to the differences in language system, cognition and cultural color, there are some differences in the expression of their syntactic structure of the measure word for noun. This study starts from the comparison of Chinese and Vietnamese languages, focusing on the meaning and structure of the measure word for noun commonly used in Chinese and Vietnamese, in order to find the similarities and differences between them.
\end{abstract}

Keywords: Measure word for noun in Chinese and Vietnamese, Semantics, Structural form

\section{Introduction}

The measure word is a major feature of Chinese and Tibetan Languages, which plays an important role in Chinese parts of speech. Because the quantity of Chinese measure words is very rich, the collocation relationship between measure words and nouns is complex, so it is difficult to master them. Vietnamese is also one of the languages with abundant measure words, but the collocation and word order of Vietnamese measure words and nouns are not completely consistent with Chinese measure words.

In this paper, Chinese measure words and Vietnamese corresponding expression units are compared to reveal the emotional color given by the use of the measure word for noun in the two languages.

We start with the comparison of Chinese and Vietnamese languages, and examine the 
meaning and structural form of the measure word for noun commonly used in Chinese and Vietnamese.

Based on the Standard and Outline of Chinese Proficiency Levels, we selected the measure word for noun used more frequently in this study. The measure word for noun selected are: 个ge; 片 pian; 块kuai; 本ben; 篇pian; 张zhang; 根gen; 棵ke; 朵duo; 双 shuang; 对dui; 副fu; 套tao; 只zhi; 条tiao; 头tou; 辆liang; 台tai; 架jia; 部bu; 粒li; 颗ke; 件jian; 把ba; 杯bei; 家jia; 所suo; 座zuo; 间jian; 位wei; 名ge; 口kou.

\section{Theoretical Background}

Chinese measure words must be collocated with nouns or verbs when they are used. This part of speech is not an open class. According to Allen's (1977) classification, in the numerical classifier language of Chinese, the order of quantifier, classifier and noun is QCN, which is the same as American languages and Vietnamese. Allen's induction is consistent with the Chinese measure words structure recognized by most grammarians (Chao, 1968; Li \& Thompson, 1981) thinks that numerals can not directly modify nouns, so it is necessary to add measure words to form the following grammatical rules.

In Chinese: demonstrator / numeral + measure word + noun; in Vietnamese, there are three kinds of structures: numeral + measure word + noun, measure word+ noun + demonstrator, numeral + noun. This part will discuss the meaning and classification of measure words in Chinese and Vietnamese.

\subsection{Definition of Chinese Measure Words}

\subsubsection{Definition}

There have been many definitions of Chinese measure words. Judging from the phenomenon of collocation of measure words and nouns in Chao (1968) and Ahren (1994), the concept of Chinese measure words has two characteristics of measurement and classification. Xiao Feiwen (2001) followed Wang Li's (1943) view of the Chinese measure words of "expressing the unit" and established it under the construction of "unit word" to express the unit of things. Chen Peijia (2000) pointed out that classifiers are used to count and explain the internal semantic functions of nouns. Tai (1994) thinks that classifiers are related to the eternal characteristics of subjects, while measure words have the characteristics of good condition. It can be seen that measure words not only have the function of "quantity", but also have the function of "classification".

\subsubsection{Classification}

According to the research results of He Jie's "Modern Chinese Measure Words Research" (2000), different scholars have different treatment of measure words classification and different classification items of measure words. However, most scholars divide "verbal measure words" into sub categories of measure words, which are juxtaposed with the classification relationship of other measure words and noun collocations, and integrate them into the following table. 
Table 1. Scholars' classification and arrangement of "the measure word for noun" (refer to Su Xinmin, 2008 and Limei Zheng, 2014)

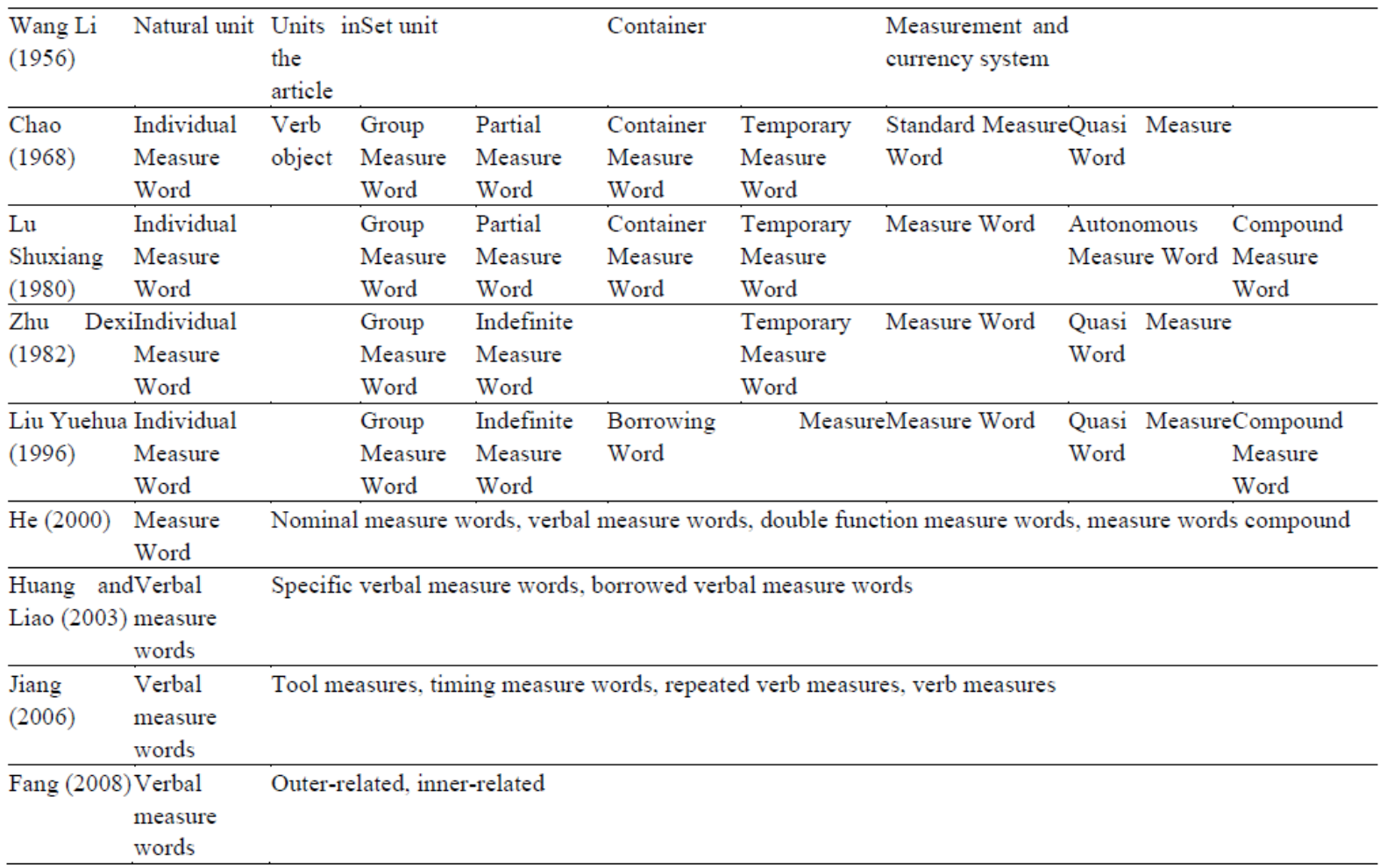

The predecessors have done a lot of research on the relationship between the collocation of measure words and nouns. Tai (1994) discusses the concept of human category division from the perspective of empiricism. He believes that the interaction between human and the surrounding environment results in the product of things classification, and it is possible that the product of each social culture may be different. However, Tai analyzed Chinese classification word system according to Allen's (1977): material, shape, consistency, size, location, arrangement, and quanta, among which location can't be used in Chinese. It's worth mentioning that Tai thinks the last two categories are measure word. Therefore, Tai adduces the viewpoint of Tversky \& Hemenway $(1983,1984)$, and brings the concept of "parts of objects and organisms" into the fifth category of Chinese classification analysis.

According to the analysis of "Bar" and "Root" by Tai (1990), although both of them can be matched with long objects, the former extends from 3D objects to 1D and 2D objects, and the latter is usually matched with hard and straight long objects. All in all, according to the research results of the above scholars, Chinese measure words occupy a special position in the language.

\subsection{Definition of Vietnamese Measure Words}

\subsubsection{Definition}

Emeneau (1951), Nguyen Tai Can (1960), Hoang Tue (1962), Ho Le (1983), Nguyen Kim Than (1963), Luu Van Lang (1970), Đinh Van Đuc (1986) all think that classifier and 
agreed unit words belong to noun category, which is a small category of nouns and can also be used to measure things.

There are different opinions on the definition of Vietnamese measure words in the field of Vietnamese linguistics, but they can be generally divided into two groups: the first group is represented by Nguyen Tai Can (1975), who regards the structure of "Measure words plus nouns" as a noun phrase, and the measure words in it as a small category of nouns, which is called "referring to unit of calculation noun". The second group regards the measure words as a separate category. For example, Lu Van Lang (1997) pointed out in Some Problems of Vietnamese Measure Words that "separating measure words from noun categories and taking them as a supplementary explanation of nouns can fully reflect the grammatical characteristics of Vietnamese measure words and noun categories". For the above two opinions, this paper agrees with the latter. We think it's more reasonable to regard measure words as independent words, which is more convenient for us to compare Chinese and Vietnamese.

\subsubsection{Classification}

At present, there are different standards and results in Vietnamese linguistic classification of measure words. Nguyen Hien Le, Truong Van Chinh (1963) classified measure words into two categories: one refers to the appellation "Quantifier" of "quantity" and the other refers to "category" named "category". Nguyen Tai Can (1975) divided it into three categories: the first category is the unit nouns that represent people; the second category is the unit nouns that represent animals and plants; and the third category is the bit nouns that represent things. Nguyen Phu Phong (2000) has different views. He divided it into four categories: collective measure words, individual measure words, degree measure words and verbal measure words.

\section{Results and Discussion}

\subsection{Comparison of Measure Words Types in Chinese and Vietnamese}

\subsubsection{The Similarity of Measure Words Types in Chinese and Vietnamese}

Chinese Measure word for noun is all classifiers, which are used in the same category of nouns, not only to measure, but also to express the nature of nouns.

There are two kinds of classifiers: individual and collective.

Chinese: 个ge; 只zhi; 把ba; 帮bang; 群qun; 组zu.

Vietnamese: cái(ge), con(zhi), nhóm(zu), đội(dui), đám(bang), đàn(qun).

The measure words in both languages can be divided into people, things, plants and things (not absolutely). Please see the table below. 
Table 2. Measure words of people, things, plants and objects in two languages

\begin{tabular}{|c|c|c|}
\hline & People & Objects \\
\hline Chinese & $\begin{array}{l}\text { 个ge, 位wei, 名 ge, 匹 pi, 头 tou, } \\
\text { 员yuan, 口kou } \begin{array}{l}\text { zhi, 尾 wei, } \\
\text { tiao }\end{array}\end{array}$ & $\begin{array}{l}\text { 只棵 ke，束 shu，株台 tai，部 bu，张 } \\
\text { 条zhu，族cu，根gen zhang，条tiao }\end{array}$ \\
\hline Vietnamese & $\begin{array}{l}\text { Ngài, người, thằng,Con } \\
\text { con, nhà }\end{array}$ & Cái, bó,khóm \\
\hline
\end{tabular}

Measure words of quantity and number

Chinese: 对dui, 副fu, 双shuang, 打da

Vietnamese: cặp, bộ, tá

Both Chinese and Vietnamese measure word for noun have classifiers that show shapes. These measure words are used to measure and show the shapes of nouns in the same or similar shapes.

Shape of the objects

Table 3. Chinese

\begin{tabular}{ll}
\hline 把ba: something with a handle or根gen: slender objects & 粒li: something small, round \\
something similar to have a handle & or grainy
\end{tabular}

Table 4. Vietnamese

Giọt: for eye drops,Cuộn: SomethingCây: A whole cigarette Thỏi: small and long dew, etc rolled into a circle things

Use corresponding nouns as temporary measure words when necessary

Chinese: 一碗汤yi wan tang, 一盒糖果yi he tangguo, 一车火龙果yi che huolongguo.

Vietnamese: một mâm cơm, một chén/tô canh, một xe thanh long, một hộp kẹo.

\subsubsection{The Difference of Chinese Measure Word for Noun Types}

Through the above comparison results, we can draw the following conclusions: the common points of Chinese and Vietnamese measure word for noun types are greater than the differences. Although the divergence is less than the convergence, the differences still exist, mainly reflected in the following aspects.

There are compound measure words in Chinese, but not in Vietnamese. In the process of continuous development and change of language, measure words belong to a member of the language system. Some of them gradually lose their original functions and are eliminated. Therefore, new measure words are born. Now there is a kind of appellation compound measure word, which is composed of different measure words, such as “班次”, “车次”, “人次”, “千瓦小时”, etc. 
Most nouns in Chinese can be modified by measure words, but Vietnamese is different. The nouns of collective organization, military organization and abstract nouns in Vietnamese cannot be modified by measure words. According to Zheng Yongxing's (2013) point of view, the nouns of collective organization and abstract nouns are both Chinese and Vietnamese words, but there is no measure words in Vietnamese vocabulary that can match these nouns, or this part of nouns does not have special measure words. Some nouns in Vietnamese have measure words to match, but they are not often used. This kind of nouns should be collocated with measure words in a certain language environment to make the expression more accurate and vivid. These nouns include: some places, surface plants, organs or human bodies, surface degrees.

In Vietnamese, measure words can be omitted between numerals and nouns when two or more numeral names are used to list or compare quantities.

\subsection{Comparison of Syntactic Structures of the Measure Word for Noun in Chinese and Vietnamese}

\subsubsection{The Syntactic Structure of Chinese Measure Words}

The main syntactic structures of Chinese measure word for noun

Table 5. Main syntactic structures of Chinese measure word for noun

\begin{tabular}{|c|c|}
\hline Example sentence & Structure \\
\hline 五杯牛奶 wu bei niunai. & Numeral + Measure word + Noun \\
\hline 这杯牛奶 zhe bei niunai. & Pronoun + Measure word + Noun \\
\hline 这五杯牛奶 zhw wu bei niu nai. & Pronoun + Numeral + Measure word + Noun \\
\hline 第五杯牛奶 di wu bei niunai. & $\begin{array}{l}\text { Prefix “第di” }+ \text { Numeral }+ \text { Measure word }+ \\
\text { Noun }\end{array}$ \\
\hline 二大杯牛奶 yi da bei niunai. & Numeral + Adjective + Measure word + Noun \\
\hline 这五辆大型客车 zhe wu liang daxin & $\begin{array}{l}\text { Pronoun }+ \text { Numeral }+ \text { Measure word }+ \\
\text { Adjective }+ \text { Noun }\end{array}$ \\
\hline 二十多个学生 er shi duo ge xuesheng. & $\begin{array}{l}\text { Numeral (more than ten digits - integer) + “多 } \\
\text { duo"+ Measure word + Noun }\end{array}$ \\
\hline 两块多钱 liang kuai duo qian. & $\begin{array}{l}\text { Numeral (less than ten digits) + Measure word } \\
+ \text { "多duo" + Noun }\end{array}$ \\
\hline
\end{tabular}

The main syntactic structures of Vietnamese measure word for noun

Table 6. Main syntactic structures of Vietnamese measure word for noun

\begin{tabular}{ll}
\hline Example sentence & Structure \\
\hline Năm ly sữa. & Numeral + Measure word + Noun \\
\hline Ly sữa này. & Measure word + noun + Pronoun \\
\hline Năm ly sữa này. & Numeral + Measure word + Noun + Pronoun \\
\hline Ly sữa thứ năm. & Measure word + Noun + Prefix “第” + Numeral \\
\hline Một ly sữa lớn. & Numeral + Measure word + Noun + Adjective \\
\hline
\end{tabular}




\begin{tabular}{ll}
\hline Năm chiếc xe khách cỡ lớn này. & $\begin{array}{l}\text { Numeral + Measure word + Noun + Adjective + } \\
\text { Pronoun }\end{array}$ \\
\hline Năm ly lớn này. & $\begin{array}{l}\text { Numeral + Measure word + Adjective + Pronoun } \\
\text { (numeral can not be "one") }\end{array}$ \\
\hline Cái ly lớn này. & Measure word + Noun+Adjective + Pronoun \\
\hline Ly lớn & Measure word + Pronoun \\
\hline Hơn 20 em học sinh & "hơn" + Numeral + Measure word + Noun \\
\hline
\end{tabular}

The characteristics of the main syntactic structures of Chinese and Vietnamese measure words

As shown in the above results, the two languages have the following characteristics:

The basic word order is exactly the same as "Numeral + Measure word + Noun".

Measure word is used only once in a noun phrase in Chinese and Vietnamese.In the basic structure "Numeral + Measure word + noun" of Chinese, the demonstrative pronouns "this" and "that" can be added in front of it. When the numeral is "one", it can be omitted, but other numeral structures cannot be omitted. The same is true in Vietnamese, but the addition of demonstrative pronouns after Chinese is the opposite.

Some adjectives can be added between numerals and measure word in two languages, but the order is different. In addition, there are three kinds of structures when the equivalent words and adjectives are collocated in Vietnamese: Numeral + Measure word + Adjective + Pronoun, Numeral + Adjective + Pronoun and Numeral + Pronoun. This is the unique structure of Vietnamese, but not in Chinese.

Two languages can add "多" to the measure word of integer with more than ten digits, but the position is different. "多" can be used for the number within 10, but not in Vietnamese.

\subsubsection{Comparison of the Reduplication of Chinese and Vietnamese Measure Words}

The reduplication form of Chinese measure word for noun is AA, but the disyllabic measure words cannot be reduplicated, and the trisyllabic measure words (mainly loanwords) cannot be reduplicated. However, most Vietnamese measure words can't be overlapped, with the exception of "người” (人) and "nhà" (家), whose form is AA type. The two languages have the same overlapping semantics, which means "all" and "every".

Besides AA, there are some other variants in Chinese. For example - AA type, - A-A type, AABB type. Add "one" before Chinese reduplication to indicate "one at a time", for example:

a. 老师把学生的作业一本本地改。 (laoshi ba xuesheng de zuoye yi ben ben di gai.)

The teacher graded the students' homework one by one.

b.她把窗户一扇扇地关上了。 (ta ba chuanghu yi shan shan di guan shang le.)

She closed the windows one by one. 
3.3 Cultural Differences Between Chinese and Vietnamese Measure Word for Noun

In Chinese, the measure words related to human beings are distinguished by dignity and inferiority. For example, "位wei" is often used to honor the addressee, but most of them are neutral words, and a few of them are derogatory.

In Vietnamese, it is the same with Chinese, and also has the distinction of dignity and inferiority. It often takes "cụ”, "ông”, "vị”, "bà” or using relative appellation words including "cụ”, "ông”, "vị”, "bà" as the respectful appellation words. The measure words with neutral color are "người" and "em", while the measure words with hate and derogatory attitude are numerous, for example, the words of "thằng", "tên", "mụ" , "kẻ" can be translated into the word "伙huo". Through the use of Vietnamese measure words, we can not only understand the speaker's attitude towards the speaker's respect and belittlement, but also know the two characteristics of the object's age and gender.

In Chinese, measure words used for animals are biased towards the results of animal observation, and the use of measure words is also very rich, such as "头", "条", "匹", etc. Contrary to Chinese, Vietnamese only uses the measure word "con" (只) to refer to it. It is not applicable to all living animals, without any emotional meaning, nor can it reflect the characteristics of animals themselves.

\section{Conclusion}

From the comparison of the type, syntactic structure and cultural color of the Noun measure words in Chinese and Vietnamese, it can be seen that the development and change of the symbolic system of language will not stop. Based on Jerzy's (1956) viewpoint, this study holds that there are different grammaticalization phenomena in Chinese and Vietnamese measure words. The grammaticalization of measure words is the self-sufficiency of language system and a problem of language evolution worthy of attention.

The limitations of the study lie in that, first, the scope of generalization of measure words is quite wide, and we can only start with the measure word with high frequency of use; second, due to the word limitation of this paper, we are not able to talk about the similarities and differences of the functions of Chinese and Vietnamese measure words, and we are also not able to talk about the circumstances when there is no need to add measure words in Vietnamese as well as its features.

\section{References}

Aikhenvald, A. Y. (2000). Classifiers: a typology of noun categorization devices. Nova York: Oxford University Press.

Deng, Sh. X. (1983). Semantic study of Chinese transitive relationship.

Deng, Sh. X. (2003a). The general principle of teaching and learning Chinese grammar in affairs. The 7th essay about teaching and learning Chinese in the world, episode 1, the Chinese in the world publishing company.

Deng, Sh. X. (2003b). The Estimated of difficulty indicator about the Chinese grammar in 


\section{IIMacrothink}

International Journal of Linguistics

ISSN 1948-5425

2021, Vol. 13, No. 1

affairs. Researching the studying and learning Chinese grammar in affairs. Beijing: the Chinese Social Science publishing company.

Duan, Y. Q. (1992). Practical Chinese grammar. Beijing: Beijing Language and Culture Unversity.

Fang, Y. (2008). On the semantic features of verbal measure words. Journal of Anqing Teachers College, 27(8), 118-121.

Gil, D. (2011). Numeral classifiers. The world atlas of language structures online. München: Max Planck Digital Library. Retrieved May 26, 2020, from http://wals.info/feature/55

Huang, B. R., \& Liao, X. D. (2003). Modern Chinese (Vol. 2). Beijing: Higher Education Press.

James, H-Y. T. (1985). Temporal sequence and Chinese word order. Huang he 1988 translated. Linguistics Abroad, 1, 10-20.

Jiang, Z. X. (2006). Semantic analysis and the matching of verbal measure words and verbs. Journal of Fuyang Teachers College (Social Science), 111(3), 50-52.

Lakoff, G., \& Johnson, M. (1999). Philosophy in the flesh. New York: Basic Books.

Liu, Y. H. (1983). Practical grammar in modern Chinese. The Publishing Company of Foreign Education and Research.

Lu, Sh. X. (1999). Modern Chinese eight hundred words. Beijing: Commercial Press.

Zhang, N. N. (2011). The constituency of classifier constructions in Mandarin Chinese. Taiwan Journal of Linguistics, 9(1), 1-50.

Zhang, N. N. (2013). Classifier Structures in Mandarin Chinese. Berlin: Mouton de Gruyter. https://doi.org/10.1515/9783110304992

Zheng, L. M. (2014). Measure words in learning and teaching Chinese as a second language. The University of Leeds.

Zhu, D. X. (1982). Teaching Grammar. Beijing: the commercial print factory.

\section{Copyrights}

Copyright for this article is retained by the author(s), with first publication rights granted to the journal.

This is an open-access article distributed under the terms and conditions of the Creative Commons Attribution license (http://creativecommons.org/licenses/by/4.0/) 